\title{
IMPLEMENTASI DIALOG OTENTIK DALAM PENGELOLAAN HUTAN DI BKPH NGARENGAN KPH PATI PERUM PERHUTANI DIVISI REGIONAL JAWA TENGAH (Authentic Dialogue Implementation on Forest Management in BKPH Ngarengan KPH Pati Perum Perhutani Central Java Regional Division)
}

\author{
Rela Pambudi ${ }^{*}$, Ahmad Maryudi ${ }^{2}$ dan Ris Hadi Purwanto ${ }^{2}$ \\ ${ }^{1}$ Program Master Ilmu Kehutanan, Fakultas Kehutanan Universitas Gadjah Mada, Jl. Agro No. 1, \\ Bulaksumur, Yogyakarta 55281. \\ ${ }^{2}$ Fakultas Kehutanan Universitas Gadjah Mada, Jl. Agro No. 1, Bulaksumur, Yogyakarta 55281.
}

*Penulis korespondensi. Tel: 085292162548. Email: rela_simbil@yahoo.com.

Diterima: 16 September 2016

Disetujui: 3 Januari 2017

\begin{abstract}
Abstrak
Perum Perhutani berusaha berkolaborasi dengan masyarakat dalam pengelolaan hutan dengan meluncurkan progam pengelolaan hutan bersama masyarakat (PHBM). Pelaksanaan PHBM di BKPH Ngarengan KPH Pati Perum Perhutani Divisi Regional Jawa Tengah saat ini terhambat karena adanya konflik dengan masyarakat. Penelitian ini berusaha mengkaji pelaksanaan PHBM di BKPH Ngarengan dari sudut pandang collaborative policymaking serta mencari solusi konflik. Penelitian ini bertujuan untuk mengetahui keragaman kepentingan dan saling ketergantungan antara masyarakat dan Perhutani dalam pengelolaan hutan serta menyusun strategi untuk menciptakan kondisi pengelolaan hutan kolaboratif. Pengambilan data dilakukan dengan pengamatan terlibat dan wawancara mendalam kepada petugas Perhutani, pengurus LMDH serta masyarakat. Analisis deskriptif digunakan untuk menggambarkan bentuk saling ketergantungan dan ragam kepentingan dalam pengelolaan hutan, sedangkan analisis SWOT digunakan untuk merumuskan strategi menuju pengelolaan hutan kolaboratif. Hasil penelitian ini yaitu terdapat bentuk ragam kepentingan dan saling ketergantungan antara masyarakat dan Perhutani dalam pengelolaan hutan. Untuk menciptakan pengelolaan hutan kolaboratif dan sebagai resolusi konflik dilakukan dengan model pengaruh politik dengan membuat program bersama berupa pengaturan jarak tanam dan pengamanan hutan bersama yang sebelumnya didahului dengan dialog otentik untuk membangun kesepahaman, tawar-menawar dan membuat kesepakatan program bersama.
\end{abstract}

Kata kunci: dialog otentik, masyarakat, pengelolaan kolaboratif, perhutani.

\begin{abstract}
Perum Perhutani efforts in a collaboration with the local community of forest management introduce Forest Management with Community (PHBM) Program. PHBM implementation in BKPH Ngarengan KPH Pati Perum Perhutani, Central Java Regional Division is currently hampered because of a conflict with the local community. This study examines the implementation of PHBM in BKPH Ngarengan from the perspective of collaborative policymaking as well as finding solutions to conflicts. This study aims to determine the diversity of interests and interdependence between community and Perhutani in forest management and develop strategies to create the conditions of collaborative forest management. Data were collected by observation and interviews with Perhutani officials, administrators of $\mathrm{LMDH}$, and the community. Descriptive analysis is used to describe the interdependence and diverse of interests in forest management, while SWOT analysis is used to formulate strategies toward collaborative forest management. Result of this research isthere is a form of diversity of interests and interdependence between community and Perhutani in forest management. To create collaborative forest management and as a model of conflict resolutioncan be carried out using political influence by creating a joint program such as plant spacing arrangement and forest security protection.which are preceded by dialogue to build understanding, bargaining and deal making programs together.
\end{abstract}

Keywords: authentic dialogue, collaborative management, community, perhutani.

\section{PENDAHULUAN}

Terbatasnya akses masyarakat ke dalam hutan yang menyebabkan masalah sosial ekonomi masyarakat sering menjadi potensi konflik antara masyarakat dan pengelola seperti banyak terjadi di Asia Selatan dan Asia Tenggara (Webb, 2007).
Permasalahan tersebut ditanggapi oleh ahli kehutanan dunia dengan mengangkat masalahmasalah sosial ekonomi dalam pertemuan kehutanan di tingkat dunia seperti World Forestry Congres (WFC) VI di Seattle 1960 dan WFC VIII di Jakarta 1978 yang membawa pesan bahwa pengelolaan hutan harus diarahkan untuk 
pembangunan masyarakat lokal (Awang, 2004) dengan melibatkan mereka dalam proses pengambilan keputusan sehingga meningkatkan kesejahteraannya (FAO, 1978). Kongres tersebutlah yang menjadi awal munculnya kehutanan sosial dan kehutanan masyarakat yang beberapa dekade terakhir telah menjadi prioritas utama dari pembuat kebijakan (Gauld, 2000). Partisipasi masyarakat dalam program ini diharapkan dapat meningkatkan kesejahteraan masyarakat, meningkatkan kapasitas dan pemberdayaan masyarakat serta meningkatkan kelestarian hutan (Maryudi dan Krott, 2012)

Pergeseran konsep pengelolaan hutan juga terjadi di Perum Perhutani. Penurunan kontrol negara atas sumberdaya hutan yang ditandai oleh penjarahan kayu besar-besaran pasca rezim Orde Baru (1998-2000) serta maraknya tuntutan desentralisasi, otonomi dalam pengelolaan sumberdaya hutan serta maraknya tuntutan partisipasi dan pemberdayaan masyarakat dalam pengelolaan hutan mendorong Perum Perhutani meluncurkan desain baru program kehutanan sosial dengan program Pengelolaan Hutan Bersama Masyarakat (PHBM) (Djamhuri, 2008). Dengan PHBM antara masyarakat dan Perhutani berbagi peran dalam proses pengambilan keputusan dan pengelolaan hutan (Maryudi, 2012) sehingga meningkatkan kesejahteraan, kualitas hidup dan kapasitas ekonomi serta sosial masyarakat (Djajanti, 2006).

Kehadiran PHBM dalam pengelolaan sumberdaya hutan diharapkan mampu menciptakan pengelolaan hutan yang lebih kolaboratif. Dalam pelaksanaan PHBM masyarakat sekitar hutan seyogyanya diberikan akses yang lebih luas dalam pengelolaan dan pemanfaatan sumberdaya hutan serta peluang untuk terlibat aktif dalam pengambilan keputusan, perencanaan kegiatan kehutanan, melakukan monitoring dan evaluasi seperti yang dirancang dalam program PHBM (Yuwono dan Putro, 2008). Masyarakat sekitar hutan bukan hanya berperan sebagai tenaga kerja, tetapi berperan sebagai subyek pengelola hutan bersama-sama Perhutani.

Sejak diluncurkannya program PHBM oleh Perhutani sampai saat ini (2015) pelaksanaan PHBM di lapangan sangat beragam, terdapat pelaksanaan PHBM yang berjalan dengan baik namun terdapat pula yang pelaksanaannya terhambat dan belum optimal seperti terjadi di BKPH Ngarengan KPH Pati Perum Perhutani Divisi Regional Jawa Tengah yang terhambat karena sering terdapat kepentingan yang tidak koheren antara masyarakat dan Perhutani sehingga menyebabkan konflik.
Permasalahan PHBM yang terdapat di BKPH Ngarengan menarik apabila dikaji menggunakan pendekatan kolaboratif. Kajian kolaboratif di tempat ini diharapkan dapat digunakan sebagai cara penyelesaian konflik yang terjadi serta menyususun strategi pengelolaan hutan kolaboratif sehingga terjadi keseimbangan peran antara masyarakat dan Perhutani. Pada akhirnya hutan tetap lestari dan masyarakat sekitar hutan tetap diakomodir kepentingannya. Tujuan dari penelitian ini yaitu untuk mengetahui bentuk keragaman kepentingan dan saling kertegantungan antara masyarakat dan Perhutani serta untuk menyusun strategi untuk menciptakan kondisi pengelolaan hutan yang kolaboratif.

\section{METODE PENELITIAN}

\section{Waktu dan Lokasi}

Penelitian ini dilakukan di BKPH Ngarengan KPH Pati Perum Perhutani Divisi Regional 1 Jawa Tengah yang secara administratif terletak di Kabupaten Pati Provinsi Jawa Tengah. Penelitian dilakukan pada bulan Maret sampai April 2015. Pengambilan sampel LMDH dilakukan terhadap 6 LMDH dari $22 \mathrm{LMDH}$ yang ada di BKPH Ngarengan. Masing-masing RPH diwakili oleh satu LMDH yang dipilih secara random.

\section{Prosedur dan Analisis Data}

Penelitian ini menggunakan pendekatan kualitatif dengan metode studi kasus. Pendekatan kualitatif digunakan untuk menjabarkan fenomena keragaman kepentingan dan saling ketergantungan antar pemangku kepentingan (stakeholders) dalam rangka pengelolaan hutan di BKPH Ngarengan. Dalam hal ini pemangku kepentingan yang dianalisis adalah Perum Perhutani dan masyarakat serta para pihak yang berkepentingan.

Data primer diperoleh secara langsung dari sumber informasi dengan melakukan pengamatan terlibat dan teknik wawancara secara mendalam (indepth interview) kepada key informan dan informan dengan alat bantu berupa panduan wawancara. Pemilihan responden dilakukan secara purposive sampling untuk pengurus LMDH dan Perhutani, secara insidental untuk petani. Key informan yang dimaksud yaitu anggota dan pengurus LMDH, kepala desa, tokoh masyarakat, petani, pihak dari Perhutani (Kepala KPH, Waka ADM, KSS PHBM, Asper dan Mantri) dan pihak terkait. Data sekunder diperoleh dengan cara mengumpulkan data dan dokumen dari Perhutani maupun kantor Desa. Untuk menjawab tujuan pertama dan kedua, analisis dilakukan secara deskriptif untuk menggambarkan bentuk saling 
ketergantungan dan bentuk ragam kepentingan dalam pengelolaan hutan antara masyarakat dan Perhutani. Untuk merumuskan strategi pengelolaan hutan kolaboratif dilakukan analisis SWOT (strenghts, weakness, opportunities, threaths).

\section{HASIL DAN PEMBAHASAN}

\section{Dinamika Pengelolaan Hutan di BKPH Ngarengan}

Dinamika pengelolaan hutan di BKPH Ngarengan dimulai saat penjarahan hutan pasca reformasi tahun 1998-1999 dan saat ini pencurian masih terjadi, ditunjukkan dengan angka tingkat pencurian kayu di BKPH Ngarengan yang paling tinggi di KPH Pati (Data pencurian KPH Pati). Eksploitasi sumberdaya alam secara illegal yang hanya mementingkan keserakahan akan berdampak pada kerusakan lingkungan (Armawi, 2013) seperti terjadi di BKPH Ngarengan saat ini. Kerusakan hutan berdampak pada erosi tanah yang tinggi sehingga sedimen tanah menyebabkan pendangkalan sungai. Petani mulai merasakan bahwa saat ini kesulitan mendapatkan air irigasi saat musim kemarau. Masyarakat juga berpendapat bahwa seringnya banjir akhir-akhir ini karena rusaknya hutan di sekitar rempat tinggal.

Dinamika pengelolaan hutan di BKPH Ngarengan tidak bisa terlepas dengan kondisi sosial ekonomi masyarakat sekitar hutan. Sebagian besar masyarakat sekitar hutan merupakan masyarakat dengan kelas ekonomi rendah. Berdasarkan data PHBM KPH Pati, Sebanyak 51,28\% masyarakat sekitar hutan berpenghasilan sebesar kurang dari Rp 500.000,00, bermatapencaharian sebagai petani sebanyak $42,60 \%$ dan buruh tani sebanyak $25,90 \%$. Kondisi seperti ini berpengaruh terhadap tekanan sumberdaya hutan.

Tanah kosong yang ditimbulkan akibat penjarahan kayu dimanfaatkan oleh masyarakat dengan menanam ketela di dalam kawasan hutan. Saat ini penanam ketela menimbulkan masalah karena meluas ke hampir seluruh kawasan BKPH Ngarengan (73\% dari total kawasan BKPH Ngarengan). Penanaman ketela menimbulkan gangguan terhadap hutan berupa pemotongan ranting tanaman pokok yang berlebihan, mematikan tanaman pokok dengan sengaja oleh petani dan meningkatkan angka pencurian pohon dengan tujuan membebaskan tanaman ketela dari naungan sehingga merugikan Perhutani.

Perhutani mengeluarkan aturan larangan penanaman ketela di dalam kawasan hutan untuk menyelesaikan masalah ketela. Namun kebijakan ini menimbulkan konflik antara masyarakat dan Perhutani sehingga menyebabkan hubungan masya-

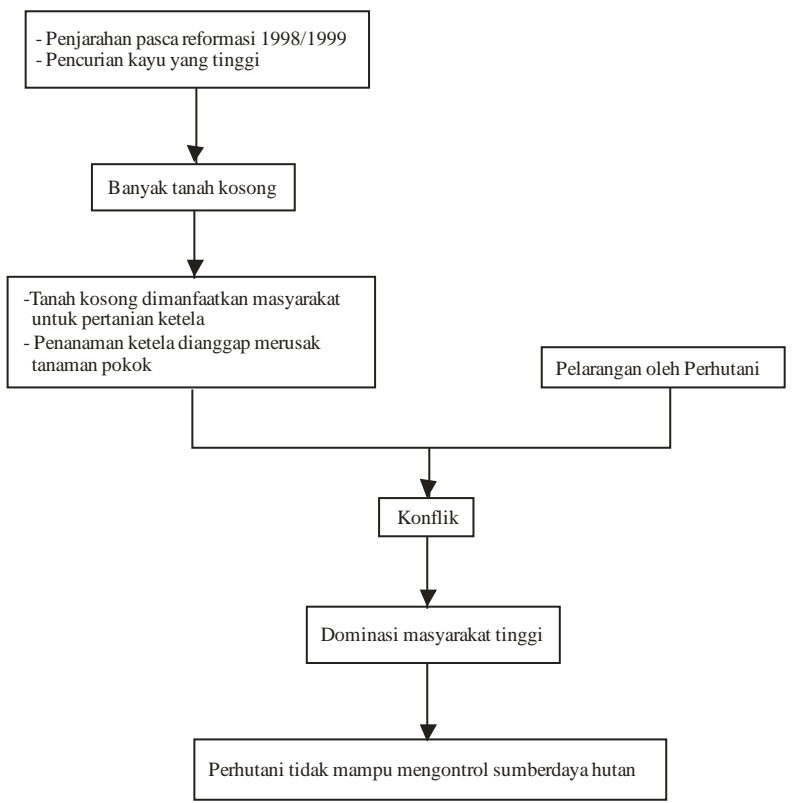

Gambar 1. Bagan dinamika pengelolaan hutan BKPH Ngarengan. Sumber : Hasil analisis.

rakat dengan Perhutani menjadi renggang sampai saat ini. Bahkan pelarangan secara represif dengan pencabutan paksa tanaman ketela sempat mendapat perlawanan fisik dari petani. Upaya yang dilakukan Perhutani saat ini sebatas pendekatan secara personal kepada petani untuk mengarahkan penanaman ketela agar tidak mengganggu tanaman pokok.

Melihat permasalahan yang dihadapi BKPH Ngarengan tersebut menunjukkan bahwa saat ini Perhutani tidak mampu mengontrol sumberdaya hutan. Perhutani sebagai pemegang mandat dari negara untuk mengelola sumberdaya hutan tidak mampu dijalankan dengan baik. Terhadap masalah yang dihadapi BKPH Ngarengan, Perhutani tidak mampu bertindak tegas terhadap oknum pencuri maupun petani. Secara umum dinamika pengelolaan hutan di BKPH Ngarengan dapat dilihat pada Gambar 1.

\section{Analisis Keragaman Kepentingan dan Saling Ketergantungan antara Masyarakat dan Perhutani}

Upaya pengelolaan hutan kolaboratif di BKPH Ngarengan telah dilakukan melalui program PHBM. Dengan skema PHBM ini masyarakat sekitar hutan dilibatkan dalam kegiatan pengelolaan hutan mulai dari perencanaan kegiatan, pelaksanaan kegiatan sampai monitoring dan evaluasi program. Namun seiring dengan berjalannya waktu, program PHBM di BKPH Ngarengan saat ini terhambat karena dipengaruhi oleh beberapa faktor di antaranya yaitu kebijakan pelarangan penanaman ketela. 
Tabel 1. Bentuk ragam kepentingan dan saling ketergantungan antara masyarakat dan Perhutani dalam pengelolaan hutan.

\begin{tabular}{|c|c|c|c|}
\hline \multicolumn{2}{|c|}{ Ragam kepentingan } & \multicolumn{2}{|c|}{ Saling ketergantungan } \\
\hline Masyarakat & Perhutani & Masyarakat & \\
\hline $\begin{array}{l}\text { - Kebutuhan lahan untuk } \\
\text { pertanian ketela } \\
\text { - Tempat mencari kayu } \\
\text { bakar } \\
\text { - Tempat mencari rumput } \\
\text { - Mendapatkan dana bagi } \\
\text { hasil (sharing) dari } \\
\text { tebangan kayu }\end{array}$ & $\begin{array}{l}\text { - } \text { Menyelenggarakan } \\
\text { pengelolaan hutan } \\
\text { sesuai tugas dan fungsi } \\
\text { pokoknya. } \\
\text { - Menciptakan } \\
\text { kelestarian hutan untuk } \\
\text { memupuk keuntungan } \\
\text { perusahaan. }\end{array}$ & 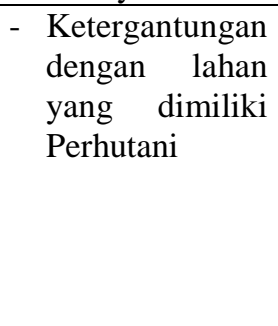 & 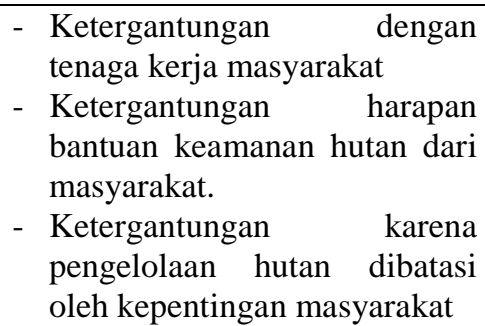 \\
\hline
\end{tabular}

Sumber: Analisis data lapangan.

Upaya pelarangan ini menjadikan konflik sehingga hubungan antara Perhutani dan masyarakat menjadi renggang dan kegiatan PHBM vakum. Innes dan Booher (2003) menyebutkan bahwa untuk mencapai kebijakan kolaboratif rasa saling ketergantungan dan ragam kepentingan harus tercipta di antara aktor yang terlibat. Apabila hanya ada satu kepentingan maka kebijakan kolaboratif tidak akan terjadi. Begitu juga apabila tidak ada rasa saling ketergantungan, yang terjadi adalah aktor-aktor tersebut akan berjalan sendiri-sendiri. Untuk mencapai pengelolaan hutan kolaboratif di BKPH Ngarengan maka dalam penelitian ini dilakukan analisis ragam kepentingan dan saling ketergantungan antara masyarakat dan Perhutani. Bentuk ragam kepentingan dan saling ketergantungan antara masyarakat dan Perhutani di BKPH Ngarengan dapat dilihat pada Tabel 1.

Hutan bagi masyarakat sekitar hutan BKPH Ngarengan mempunyai peran yang sangat besar dan merupakan salah satu penopang hidup. Hutan dipandang dapat meningkatkan kesejahteraan masyarakat melalui pertanian ketela, sumber pakan ternak dan kayu bakar serta bagi hasil tebangan kayu sesuai skema program PHBM. Sedangkan bagi Perhutani hutan merupakan mandat dari negara yang harus dikelola secara lestari serta memberikan pendapatan bagi negara.

Dalam pengelolaan hutan di BKPH Ngarengan antara masyarakat dan Perhutani terdapat saling ketergantungan. Masyarakat bergantung dengan Perhutani karena keterbatasan sumberdaya lahan untuk pertanian ketela. Begitu juga sebalikanya, Perhutani bergantung dengan masyarakat karena keterbatasan sumberdaya untuk mendukung pencapaian kepentingan Perhutani yaitu terciptanya hutan yang lestari. Perhutani sangat membutuhkan tenaga kerja dari masyarakat dan bantuan keamanan hutan. Ketergantungan Perhutani terhadap masyarakat juga tercermin pada ketidakmampuan Perhutani dalam mengatur masyarakat karena dominasi masyarakat dalam konflik sangat besar sehingga gerak Perhutani dalam pengelolaan hutan tergantung kepada masyarakat.

\section{Analisis Kolaboratif: Evaluasi pelaksanaan PHBM di BKPH Ngarengan}

Analisis kolaboratif bertujuan untuk mengetahui sejauh mana pelaksanaan PHBM di BKPH Ngarengan dijalankan dengan prinsipprinsip kolaboratif. Prinsip-prinsip dalam pendekatan kolaboratif menurut Innes dan Booher (2003) bahwa : pertama, setiap pemangku kepentingan (stakeholder) harus menyadari posisinya. Mereka tidak bisa begitu saja menyerah atau sebaliknya bersikeras dengan kepentingan mereka sendiri. Kedua, mereka harus belajar dan mengenal satu sama lain. Ketiga, mereka harus mencari solusi bersama yang sejauh mungkin memenuhi semua kepentingan. Keempat, mereka harus dapat bertahan dalam 2 (dua) kondisi, yaitu bersaing dan bekerjasama dalam rangka pengambilan kebijakan. Kelima, ketegangan antara persaingan dan kerjasama adalah inti dari kolaborasi.

Menurut Innes dan Booher (2003), terdapat 4 (empat) hal yang terjadi dalam pendekatan kolaboratif, yaitu timbal balik (reciprocity), hubungan baik (relationships), pembelajaran (learning) dan kreativitas (creativity). Oleh karena itu, analisis kolaboratif dilakukan dengan mengidentifikasi 4 (empat) hal tersebut. Hasil pelaksanaan PHBM di BKPH Ngarengan dapat dilihat pada Tabel 2.

Hubungan timbal balik antara Perhutani dan masyarakat belum sesuai dengan yang diharapkan dalam program PHBM. Pertanian ketela oleh masyarakat justru merusak tanaman pokok karena masyarakat melakukan pemangkasan cabang secara berlebihan. Dukungan keamanan dan perlindungan hutan dari masyarakat juga belum terjadi. Hubungan antara masyarakat dan Perhutani saat ini tidak baik karena konflik akibat pelarangan penanaman ketela. 
Tabel 2. Hasil pelaksanaan PHBM di BKPH Ngarengan.

\begin{tabular}{ll}
\hline Aspek & Keterangan \\
\hline Hubungan timbal balik & $\begin{array}{l}\text { Hubungan timbal balik belum terjadi secara dua arah. Perhutani belum mendapat } \\
\text { keuntungan dari program PHBM, bahkan Perhutani sebagai pihak yang dirugikan. }\end{array}$ \\
Hubungan baik & $\begin{array}{l}\text { Dengan adanya PHBM terdapat hubungan yang lebih baik. Namun saat ini menjadi } \\
\text { kurang baik karena konflik akibat pelarangan penanaman ketela. }\end{array}$ \\
Pembelajaran & $\begin{array}{l}\text { Sudah ada upaya proses pembelajaran melalui pertemuan keduabelah pihak untuk } \\
\text { memecahkan masalah. Namun begitu hasil pembelajaran belum terasa. }\end{array}$ \\
Kreativitas & Belum nampak kreativitas yang dihasilkan untuk menyelesaikan masalah. \\
Sumber: Analisis data lapangan.
\end{tabular}

Tabel 3. Bentuk adaptasi pelaksanaan PHBM di BKPH Ngarengan.

\begin{tabular}{ll}
\hline Aspek & Keterangan \\
\hline Identitas bersama & $\begin{array}{l}\text { Sebagian besar anggota LMDH tidak mengetahui peran dan posisinya di dalam } \\
\text { program PHBM. }\end{array}$ \\
Pemahaman bersama & $\begin{array}{l}\text { Antara masyarakat dan Perhutani belum terjadi kesepahaman bersama dan masih } \\
\text { terjadi konflik kepentingan. }\end{array}$ \\
Heuristik/norma baru & $\begin{array}{l}\text { Rasa saling menghormati belum terbentuk, antara masyarakat dan Perhutani masih } \\
\text { mementingkan kepentingannya sendiri }\end{array}$ \\
Inovasi & $\begin{array}{l}\text { Inovasi yang dapat mengakomodir kepentingan masyarakat dan Perhutani belum } \\
\text { terbentuk }\end{array}$ \\
\hline
\end{tabular}

Sumber: Analisis data lapangan.

Upaya pembelajaran melalui pertemuan keduabelah pihak sudah pernah dilaksanakan saat awal pelaksanaan program PHBM, namun begitu hasil pembelajaran bersama belum terasa terbukti masalah konflik dan pencurian kayu belum terselesaikan. Dari permasalahan yang belum terselesaikan maka dapat dikatakan kreatifitas dari hasil program PHBM belum nampak. Pengelolaan kolaboratif akan membawa perubahan yang mengakibatkan adaptasi dari suatu sistem. Innes dan Booher (2003) menyebutkan bahwa perubahan tersebut adalah identitas bersama, pemahaman bersama, norma baru dan inovasi. Analisis bentuk adapatasi pengelolaan kolaboratif juga dilakukan dalam penelitian ini. Hasil adaptasi dari program PHBM di BKPH Ngarengan dapat dilihat pada Tabel 3.

Sebagai aktor yang terlibat dalam program PHBM, sebagian besar anggota LMDH tidak mengetahui peran dan posisinya serta hak dan kewajibannya. Mereka seharusnya memahami identitasnya dalam sebuah sistem sehingga tahu mengenai apa yang harus dilakukan. Kesepahaman bersama antara masyarakat dan Perhutani dalam pengelolaan hutan juga belum terjadi. Kesadaran masyarakat mengenai fungsi hutan masih rendah sehingga mereka kurang peduli terhadap kelestarian hutan.

Rasa saling menghormati sebagai bentuk adaptasi pengelolaan hutan bersama belum terlihat sehingga masyarakat masih mementingkan kepentingannya sendiri dengan menanam ketela dan mengabaikan aturan yang telah dikeluarkan oleh Perhutani, begitu juga dengan Perhutani yang kurang memahami ketergantungan masyarakat terhadap ketela dengan tetap melarang penanaman ketela di dalam kawasan hutan. Ide-ide baru yang inovatif juga belum terjadi dalam pengelolaan hutan di BKPH Ngarengan. Keputusan yang diambil untuk mengatasi masalah bersama yang dapat mengakomodir semua kepentingan dengan win-win solutions belum terjadi.

\section{Model Pengaruh Politik Sebagai Strategi Kolaboratif dalam Upaya Resolusi Konflik dan pelestarian lingkungan}

Pendekatan kolaboratif muncul sebagai respon atas tuntutan kebutuhan akan manajemen pengelolaan sumberdaya alam yang lebih mengakomodir kepentingan berbagai pihak yang berkepentingan. Kolaborasi dianggap sebagai cara untuk mengurangi konflik antara para pemangku kepentingan, membangun modal sosial, perbaikan lingkungan dan sosial ekonomi yang harus ditangani secara bersama-sama sehingga menghasilkan keputusan yang lebih baik (Weber, 2000) dan saat ini dipromosikan sebagai cara yang menjajikan untuk menangani sumberdaya alam dengan berbagai masalah yang kompleks (Conley dan Moote, 2003).

Konflik antara masyarakat dan Perhutani di BKPH Ngarengan terjadi karena terdapat ragam kepentingan terhadap sumberdaya hutan yang berseberangan. Kepentingan masyarakat untuk menanam ketela berseberangan dengan kepentingan Perhutani untuk membangun hutan yang lestari. Kedua belah pihak saling berusaha untuk mencapai kepentingannya sehingga keragaman kepentingan 
yang tidak selaras ini menimbulkan konflik. Posisi masyarakat dalam konflik yang terjadi di BKPH Ngarengan ini lebih dominan dibanding dengan Perhutani. Perhutani sebagai pemegang mandat mengelola hutan tidak mampu mengatur masyarakat.

Konflik yang terjadi di BKPH Ngarengan berpotensi apabila diselesaikan dengan pendekatan kolaboratif. Antara masyarakat dan Perhutani terdapat saling ketergantungan dan ragam kepentingan sebagai modal untuk berkolaborasi. Konflik yang terjadi di BKPH Ngarengan tidak menjadi penghalang untuk berkolaborasi tetapi dapat dijadikan sebagai insentif untuk menciptakan pengelolaan hutan kolaboratif. Ansell and Gash (2007) menyebutkan bahwa ketika para pemangku kepentingan sangat saling tergantung dan tingkat konflik yang tinggi dapat benar-benar menciptakan insentif yang kuat untuk mendorong kolaborasi.

Melihat kondisi di lapangan saat ini, ragam kepentingan antara masyarakat dan Perhutani termasuk tinggi dengan intensitas yang kuat. Ragam kepentingan yang kuat yaitu terletak pada perebutan pemanfaatan sumberdaya lahan sehingga di antara keduanya timbul konflik, sedangkan saling ketergantungan di antara mereka tidak begitu kuat. Walaupun Perhutani tergantung dengan tenaga kerja dari masyarakat sekitar hutan, Perhutani dapat mencari tenaga kerja dari daerah lain. Selain itu harapan bantuan keamanan dari masyarakat juga tidak begitu dapat diandalkan. Kondisi sebaliknya masyarakat sangat tergantung dengan Perhutani dengan lahan yang dimiliki oleh Perhutani.

Dengan kondisi ragam kepentingan yang tinggi dan saling ketergantungan yang rendah maka bentuk perencanaan yang dapat dipilih yaitu model pengaruh politik (Innes dan Booher, 2003). Model pengaruh politik melibatkan pemimpin dengan pengaruh yang kuat biasanya berbasis proyek dan mempunyai kekuasaan dari loyalitas yang tinggi. Tujuan pengaruh politik adalah bahwa para stakeholder yang kuat dan pejabat yang terpilih memiliki proyek dan program yang mereka dapat lakukan. Pemimpin itu kemudian memiliki legitimasi politik untuk tawar-menawar dengan orang lain dan komunitas untuk memiliki sumber daya. Model ini mempertahankan politik perdamaian.

Dalam perencanaan model pengaruh politik di BKPH Ngarengan, aktor yang berpotensi dilibatkan dalam proses tawar menawar yaitu Perhutani, Pengurus LMDH, Kepala Desa dan tokoh masyarakat. Pengurus LMDH, Kepala Desa dan tokoh masyarakat cukup mempunyai pengaruh yang kuat terhadap masyarakat dan mampu bernegosiasi dengan Perhutani. Hasil yang diharapkan yaitu menghasilkan kesepakatan winwin solutions dan menciptakan suatu program bersama untuk menyelesaikan konflik. Pengurus LMDH, Kepala Desa dan tokoh masyarakat diharapkan mampu menyampaikan dan mempengaruhi kepada masyarakat luas mengenai hasil kesepakatan yang dibuat.

Untuk menyusun strategi pengelolaan hutan kolaboratif, dalam penelitian ini dilakukan analisis SWOT. Bentuk strenght untuk mendukung pengelolaan kolaboratif yaitu antara masyarakat dan Perhutani terdapat saling ketergantungan dan Perhutani mempunyai kemauan untuk berkolaborasi, masyarakat juga menyadari akan kesalahnnya. Sementara itu terdapat weakness untuk mendukung pengelolaan kolaboratif yaitu antara masyarakat dan Perhutani belum terdapat kesepahaman dalam pengelolaan hutan serta kesadaran masyarakat mengenai fungsi hutan rendah, sebagian besar masyarakat juga belum mengetahui peran dan posisinya dalam PHBM. Opportunity untuk mendukung pengelolaan kolaboratif yaitu terdapat dukungan pemerintah desa untuk menyelesaikan konflik, kelembagaan LMDH sudah terbentuk dan Perhutani memberikan hak garap di bawah tegakan. Bentuk threaths untuk mendukung pengelolaan kolaboratif yaitu kelembagaan LMDH vakum, aturan larangan penanaman ketela dan pencurian kayu yang tinggi.

Bentuk strategi yang dihasilkan dari kajian SWOT yaitu (1) Membangun dialog otentik, (2) Pengaturan jarak tanam dan keamanan hutan bersama (3) Mengevaluasi aturan larangan penanaman ketela dan (4) Optimalisasi dan peningkatan kapasitas LMDH. Strategi tersebut disusun dengan skema seperti Gambar 2.

Strategi dialog otentik merupakan kunci dari perdamaian untuk membangun kesepahaman, proses tawar menawar dan membuat kesepakatan untuk menciptakan pengelolaan hutan kolaboratif. Pengaturan jarak tanam dan pengamanan hutan bersama diharapkan menjadi program bersama yang mampu mengakomodasi kepentingan masyarakat dan Perhutani. Hal ini didasarkan karena Perhutani dan masyarakat saling membutuhkan lahan. Strategi evaluasi aturan larangan penanaman ketela dan optimalisasi serta peningkatan kapasitas LMDH dapat menjadi strategi untuk mendukung program bersama. Strategi-strategi tersebut diharapkan mampu mengakomodasi kepentingan Perhutani dan Masyarakat sehingga dapat meredam konflik dan menciptakan pengelolaan kolaboratif yang win-win solutions. 
Dialog otentik sebaiknya diinisiasi oleh Perhutani dengan melibatkan LMDH, Pemerintah Desa dan tokoh masyarakat. Perhutani sebagai inisiator karena merupakan pihak yang mempunyai kepentingan untuk mengatasi konflik. LMDH, pemerintah desa dan tokoh masyarakat dipilih dalam melakukan dialog otentik ini karena dianggap dapat mempresentasikan kepentingan masyarakat dan mempunyai pengaruh yang besar terhadap masyarakat. Konsep dalam dialog otentik diarahkan untuk menghasilkan program bersama yang bijak dan mampu mengakomodir kepentingan masyarakat dan Perhutani. Program bersama tersebut nantinya akan dijadikan model pengaruh politik yang disampaikan kepada masyarakat oleh LMDH, Pemerintah desa dan tokoh masyarakat.

Dalam strategi pengelolaan hutan kolaboratif di BKPH Ngarengan, pengaturan jarak tanam dan pengamanan hutan bersama dapat menjadi alternatif program bersama dan dijadikan sebagai model pengaruh politik. Pemilihan strategi pengaturan jarak tanam didasarkan pada kepentingan Perhutani dan masyarakat yang saling membutuhkan lahan sehingga harus ada pembagian ruang tumbuh antara tanaman kehutanan dan tanaman pertanian, sebagai timbal baliknya Perhutani mendapat bantuan keamanan dari masyarakat. Ada beberapa konsep pengaturan jarak tanam misalnya konsep management regime (MR) yang memberi hak kepada masyarakat untuk mengelola lahan pertanian di areal hutan dengan membentuk jalur pertanian baru (Simon, 2001).

Pengaturan jarak tanam dinilai cocok diterapkan di BKPH Ngarengan sebagai strategi mengatasi konflik dan menuju pengelolaan kolaboratif karena tekanan masyarakat terhadap hutan saat ini tinggi. Masyarakat mempunyai keterbatasan lahan pertanian sehingga dengan pola jarak tanam yang lebih lebar masyarakat mendapatkan lahan pertanian baru. Pengaturan jarak tanam dapat dijadikan sebagai insentif bagi masyarakat sekitar hutan agar mau bekerjasama dan berkolaborasi dalam pengelolaan hutan.

Pelaksanaan program pengaturan jarak tanam dan pengamanan hutan sangat membutuhkan peran dari LMDH, pemerintah desa dan tokoh masyarakat. Pihak-pihak tersebut berperan dalam menyampaikan program terebut kepada masyarakat dalam bentuk pengaruh politik. Semuanya harus mampu meyakinkan bahwa program tersebut merupakan program yang paling bijak dan benar sehingga masyarakat mau mengikuti program tersebut.

Strategi evaluasi aturan larangan penanaman ketela di dalam kawasan hutan merupakan dukungan terhadap program bersama. Setelah peng-

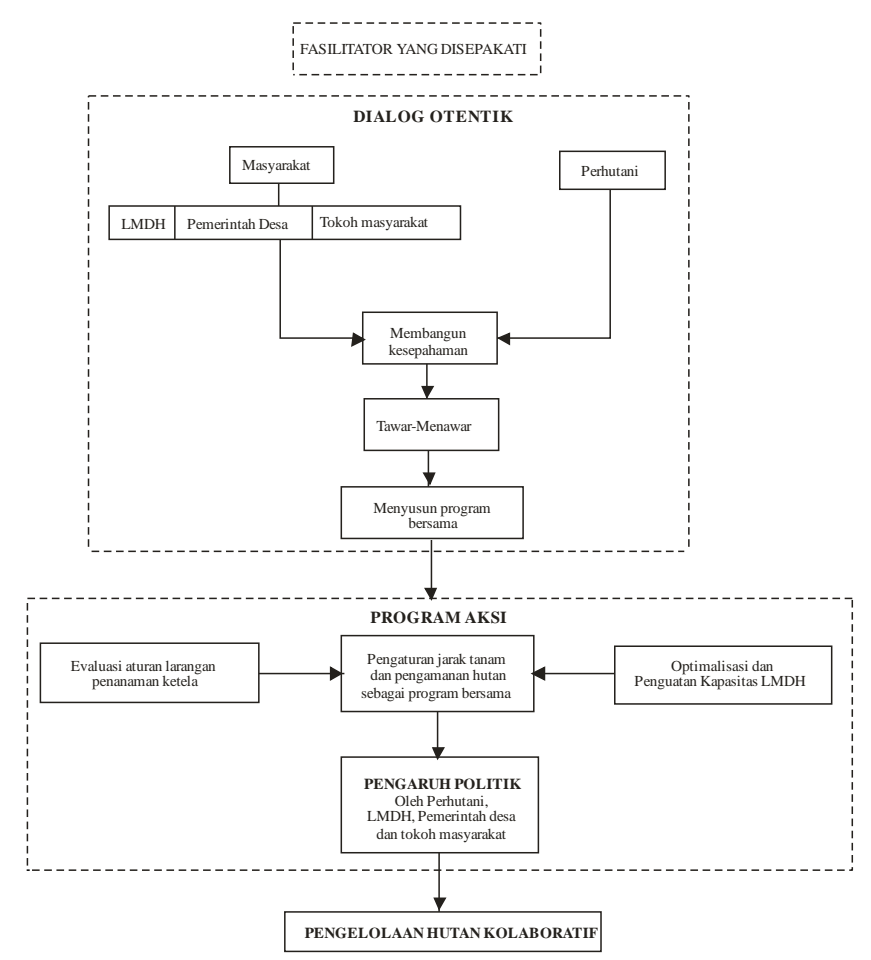

Gambar 2. Strategi pengelolaan hutan kolaboratif BKPH Ngarengan.

aturan jarak tanam berjalan maka aturan larangan penanaman ketela di dalam kawasan hutan harus ditinjau lagi. Strategi ini dipilih karena aturan Perhutani yang melarang penanaman ketela di dalam kawasan hutan merupakan pemicu konflik antara masyarakat dan Perhutani.

Optimalisasi dan peningkatan kapasitas LMDH penting dilakukan untuk mendukung strategi pengelolaan hutan kolaboratif di BKPH Ngarengan. Keberadaan LMDH sangat penting sebagai wadah yang mempresentasikan masyarakat desa hutan. LMDH sangat berperan dalam menjalankan pengaruh politik kepada masyarakat atas program bersama yang telah dibuat. Oleh karena itu kondisi kelembagaan LMDH harus diperbaiki untuk mendukung strategi pengelolaan hutan kolaboratif. Peningkatan karakteristik individu anggota seperti semangat belajar inovatif, rasa kompeten, semangat kerja sama dan motivasi kerja juga harus ditingkatkan untuk mendukung good forestry governance (Atmojo dkk., 2013)

Tujuan optimalisasi dan peningkatan kapasitas LMDH yaitu agar dapat meningkatkan peran LMDH dalam pengelolaan hutan melalui konsep PHBM. Dengan strategi ini diharapkan LMDH mampu menjadi mitra Perhutani dan berkolaborasi dalam pengelolaan hutan. LMDH diharapkan dapat digunakan sebagai wadah yang mempresentasikan masyarakat sekitar hutan sehingga kepentingan anggotanya dapat diakomodir. Selain itu LMDH 
diharapkan mampu meningkatkan kesadaran bagi anggota mengenai fungsi hutan dan pentingnya kelestarian hutan. Dengan peningkatan kapasitas LMDH juga diharapkan mampu membantu Perhutani dalam perlindungan dan keamanan hutan.

Upaya optimalisasi dan peningkatan kapasitas LMDH dilakukan dengan cara (1) peningkatan kualitas pengurus LMDH yang fasilitatif, mampu mengakomodir kepentingan anggotanya, mendistribusikan manfaat PHBM secara adil dan merata kepada anggotanya serta mampu menjadi jembatan penghubung antara masyarakat dan Perhutani dalam pengelolaan hutan, (2) penataan keanggotaan LMDH sehingga mudah dikoordinir dan (3) penguatan kelembagaan melalui penyempurnaan aturan-aturan internal LMDH dan hak kewajiban anggota dalam program PHBM. Hasil yang diharapkan yaitu peningkatan kemampuan lembaga dalam pengelolaan lembaga serta mendorong lembaga untuk memiliki kekuatan dalam menghadapi dan berinterkasi dengan pihak luar.

Upaya pengelolaan hutan kolaboratif di BKPH Ngarengan sebagai salah satu aplikasi konsep kehutanan masyarakat diharapkan dapat meningkatkan kelestarian hutan dan perbaikan lingkungan. Seperti disebutkan oleh Maryudi, dkk (2012) bahwa salah satu tujuan kehutanan masyarakat yaitu untuk perbaikan kondisi hutan. Melalui kerjasama dalam pengamanan hutan diharapkan tingkat pencurian kayu menurun sehingga kelestarian hutan tercapai. Dengan pengaturan jarak tanam yang telah disepakati diharapkan kerusakan hutan akibat penanaman ketela tidak terjadi lagi. Optimalisasi dan peningkatan kapasitas LMDH diharapkan dapat meningkatkan kesadaran anggota untuk melestarikan lingkungan.

\section{KESIMPULAN}

Bentuk kepentingan masyarakat sekitar hutan di BKPH Ngarengan terhadap sumberdaya hutan yaitu kebutuhan lahan garapan untuk pertanian ketela, sumber pakan ternak, kayu bakar dan kepentingan untuk mendapatkan dana bagi hasil dari tebangan kayu (sharing). Sedangkan bentuk kepentingan Perhutani terhadap sumberdaya hutan yaitu terciptanya pengelolaan hutan yang lestari dan memberikan keuntungan bagi perusahaan sesuai tugas dan fungsi pokoknya. Masyarakat memiliki ketergantungan dengan Perhutani berupa ketergantungan terhadap sumberdaya lahan yang dimiliki Perhutani, sedangkan Perhutani tergantung dengan masyarakat karena tenaga kerja yang dimiliki masyarakat, harapan bantuan keamanan hutan dari masyarakat dan ketergantungan karena pengelolaan hutan dibatasi kepentingan masyarakat.

Konflik di BKPH Ngarengan berpotensi diselesaikan dengan model pengaruh politik dalam skema pengelolaan hutan kolaboratif. Perhutani, LMDH, pemerintah desa dan tokoh masyarakat melakukan dialog otentik untuk membangun kesepahaman, tawar-menawar dan membuat kesepakatan program bersama dalam rangka pengelolaan hutan kolaboratif. Tawaran program bersama dalam penelitian ini yaitu pengaturan jarak tanam dan pengamanan hutan bersama. Program bersama ini didukung dengan strategi evaluasi aturan larangan penanaman ketela dan optimalisasi serta peningkatan kapasitas LMDH.

Upaya penyelesaian konflik di BKPH Ngarengan membutuhkan keseriusan dan kemauan Perhutani. Kepentingan masyarakat berupa kebutuhan lahan garapan untuk pertanian ketela sebaiknya diakomodir. Pendampingan terhadap LMDH juga perlu dilakukan sebagai upaya optimalisasi dan peningkatan kapasitasnya. Masalah gangguan terhadap hutan tidak bisa terlepas dari masalah kemiskinan masyarakat sekitar hutan. Oleh karena itu, Perhutani sebaiknya melibatkan pihak lain seperti pemerintah maupun swasta lain untuk menciptakan lapangan pekerjaan sehingga dapat mengurangi beban tekanan masyarakat terhadap hutan.

\section{UCAPAN TERIMAKASIH}

Penulis menyampaikan ucapan terima kasih kepada beasiswa dan pengelola beasiswa ISB (In Search of Balance). Penelitian ini didanai oleh program ISB, kerjasama Universitas Gadjah Mada Yogyakarta dan Universitas Agder Norwegia.

\section{DAFTAR PUSTAKA}

Ansell, C dan Gash, A, 2007. Collaborative Governance in Theory and Practice. Journal of Public Administration Research and Theory, 18: 543-571.

Armawi, A., 2013. Kajian Filosofis Terhadap Pemikiran Human-Ekologi dalam Pemanfaatan Sumberdaya Alam. Jurnal Manusia dan Lingkungan, 20(1): 57-67.

Atmojo, T., Awang, S.A., Purwanto, E.A., 2013. Pengaruh Karakteristik Individu Terhadap Good Forestry Governance di Taman Nasional Alas Purwo. Jurnal Manusia dan Lingkungan, 20(2):153-163.

Awang, S.A., 2004. Dekonstruksi Sosial Forestri: Reposisi Masyarakat dan Keadilan Lingkungan. Bigraf, Yogyakarta. 
Conley, A. dan Moote, M.A., 2003. Evaluating Collaborative Natural Resource Management. Journal of Society and Natural Resources, 16:371-386

Djajanti, D. 2006. Managing Forest with Community (PHBM) in Central Java: Promoting Equity in Access to NTFPs. Dalam Mahanty, S. Fox, J., Nurse, M. Stephen, P. dan McLees, L. Hanging In the Balance: Equity in Community-Based Natural Resource Management in Asia. RECOFTC, Bangkok and East-West Center, Honolulu. p.63-82

Djamhuri, T.L., 2008. Community Participation in A Social Forestry Program in Central Java, Indonesia: The Effect of Incentive Structure and Social Capital. Journal of Agroforest, 74:83-96

FAO, 1978. Forestry for Local Community Development. Food and Agriculture Organization of the United Nations (FAO), FAO Forestry Paper, No.7, Rome.

Innes, J.E. dan Booher, D.E., 2003. Collaborative Policymaking: Governance Through Dialogue. Dalam Hajer, Maarten A., dan Henderik Wagenaar. Deliberative Policy Analysis. Understanding Governance in The Network Society. Cambridge University Press, Cambridge p. 33-59

Gauld, R., 2000, Maintaining Centralized Control in Community-Based Forestry: Policyconstruction in The Philippines. Journal Development and Change, 31:229-254.
Maryudi, A., 2012, The Development of Community Forestry in Indonesia. RECOFTC-The Center for People and Forests, Bangkok.

Maryudi, A dan Krott, M., 2012. Poverty Alleviation Effort through a Community Forestry in Java, Indonesia. Journal of Suistanable Development, 5(2):43-53.

Maryudi, A., Devkota, R.R., Schusser, C., Yufanyi, C., Aurenhammer, H., Rotchanaphatharawit, R., Krott, M., 2012., Back to Basic: Considerations in Evaluating the Outcomes of Community Forestry. Journal Forest Policy and Economics, 14(1):1-5.

Simon, H. 2001. Pengelolaan Hutan Bersama Rakyat (Cooperative Forest Management). Teori dan Aplikasi Pada Hutan Jati di Jawa. Bigraf Publishing. Yogyakarta.

Webb, E.L., 2007, Forest Policy as a Changing Context in Asia. Dalam Webb, E.L. dan Shivakoti, G.P. Decentralization, Forests and Rural Communities: Policy Outcomes in South and Southeast Asia. SAGE Publication. New Delhi p. 21-43.

Weber, E., 2000, A New Vanguard for The Environment: Grass-Roots Ecosystem Management as A New Environmental Movement. Journal Society Nat. Resources, 13(3):237-259.

Yuwono, T., dan Wiyono T.P., 2008, Cooperative Forest Management: Potret Pengelolaan Hutan Kabupaten Ngawi di Era Otonomi Daerah. Datamedia. Yogyakarta. 